\title{
Research on Interesting Expression of Fashion Design
}

\author{
Xiaoling Chen ${ }^{1}$
}

\author{
${ }^{1}$ Jiangxi Institute of Clothing Technology, Nan Chang, Jiang Xi, 330038
}

\section{KEYWORDS: Fashion Design, Fun, Expression Form}

\begin{abstract}
With the progress of economic development and accelerating the speed of the current science and technology, people's standard of living is also rising. People's material needs are met, but also increasingly focused on demand from the spiritual level, which also contributed to people's creativity and aesthetic began to change. Fast-paced lifestyle people are more tired of the monotony of modernism and rigid style. In the consumer market, many young people, led by consumer groups gradually began to pursue personal, this aesthetic entertaining but also to a lot of contemporary designers presented new challenges. Especially in clothing design, people gradually tend to the needs of fun and personalization. This article will briefly explore the interesting expression of fashion design, clothing design our hope to provide some help, and to reference.
\end{abstract}

\section{Introduction}

With the development of society, people gradually got tired of the traditional single lifestyle. This also results in fashion design more designers began to inherit a people-centered beliefs, people psychological needs gradually pay attention to it. Interesting expression fashion design is simple, has an affinity for languages, so that clothing fun to be expressed, encourage consumers to get psychological satisfaction and pleasure, so that consumers are fully arouse curiosity, to enhance the attractiveness of clothing. Fun designed to allow consumers to effectively meet the spiritual needs, let the aesthetic and psychological sense of pleasure people get fully aroused. It can give a strange sense of familiarity, so that information can be communicated effectively to achieve the purpose.

\section{The Fun of Fashion Design style}

In the traditional art style has a very important role and status and it is not a sign of a successful artist. Many in the beginning stages of design creation, we cannot exhibit the correct intentions, ideas, meaning, technique and material, the uncertainty of this creative process is also a lot of work style is difficult to be effectively determined. In art and design industry, this cannot determine the style of the design is that recognized by the people [1]. But in the field of fashion design, but it has not the same phenomenon, costume design process, can freely mix and match a variety of materials, styles and even style, by one element can be a variety of styles to show up, a style of clothing can be demonstrated a variety of elements. The concept of modern fashion design is mostly to break the traditional style, but also make part of their unique style to create it. Modern design does not define the more significant, no matter what style are able to show in a different clothing line design. Designer style will not suffer from the shackles in the design process to express ideas more attention, a lot of design ideas of thinking, it is possible to obtain very high recognition and praise, vague and diverse style, to promote fashion design style show a unique interest, and by modern consumers, especially young consumers about twenty. 


\section{The Interest Expressed by the Elements Configuration in Fashion Design}

In the plastic arts in fashion design has a certain particularity, which is mainly composed of four elements of an art language, style, pattern, fabric and color, allowing designers to design effective expression. Through continuous arrangement and designer styles, colors, patterns and other practical combination of elements of clothing, every design element links between designers are showing design concepts, these design elements are able to express interest, or even the whole process design can express interest [2]. Thus, with the clothing element configurations fun expression, the expression has a larger space for the expression of interest as a theme designer must be by means of creative design costume elements. Costume design interesting in the field of fashion design use very extensive, therefore, requiring designers to give full play to the imagination between design, into their own inspiration to be able to occupy a seat position from interest in the field of fashion design.

Clothing style design that allows two-dimensional design thinking is gradually converted into three-dimensional space, so that a sense of body styles to be realized, prompting visual effect is more intense, but also to a large extent be increased so that clothing interesting. Due to current artistic trends affect future shape of fashion design, fashion design modern traditional clothing structure gradually bound gradually broken, so that clothing style gradually to a new form of conventional outside to get performance, body structure and make great differences clothing structure was created [3]. Let the order and the integrity of the structure to accompany the traditional clothing damage, prompting the United States Clothing incomplete gradually accepted and loved by the people. Weird shapes on the exaggerated and gradually formed an art, it encourages traditional image is changed, with a strong new ideas, let people unexpectedly, arrived in a different kind of beauty, full fun.

With the continuous development of clothing, people tend to gradually clothing is personalized and traditional clothing materials increasingly unable to make people's needs are met, which also led to greater attention from the design of clothing. Therefore, many designers also gradually on fabric innovation, non-woven material is gradually being applied to fashion design, so that more new shape gradually produced by means of fabric re-design, costume design to promote effective demand gradually to show the clothing aesthetic development of the fabric recycling judge. The styles, colors and materials, such as clothing elements previously not able to start gradually appearing simultaneously together with the gradual integration of irrelevant things from the past [4]. For example: in clothing design, the two fabrics of silk and plastic integration, so that the traditional silk fabrics, elegant style to be broken up, prompting the modern avant-garde style has been effectively demonstrated; lace and metallic leather or integration, so that soft and hard, transparent and thick, the combination of virtual and real, so effective street punk show, prompting the formation of a new visual effects. In addition, also by means of special clothing crafts, fabrics by secondary recycling method, so that the formation of the fabric fold effect, thus contributing to the shape of the fabric of diversity to be reflected. For example: by origami method, ironing fabric to shape, and then folded into vivid, with interesting texture and so on.

Clothing color different mixes can be an important factor in large part to highlight the novelty of clothing, which is able to attract the eye. Traditional clothing with a more conservative color, mostly using approximate color and harmonic color; modern clothing design, the color is more abundant, mostly using the complementary color contrast and exaggerated contrast color contrast and so on, with the help of a variety of means to innovate such as brightness contrast color, contrast and hue purity and contrast and well-being, so that richer color emotional effect can be achieved. Tsumori Chisato is a famous Japanese fashion designer, she was in the design process, the 
traditional clothing of their own national culture concept avoided, but in the warm clothing to show Japanese women do not want to grow up, pure fantasy and emotion, use mix and match colors cartoon graphics show you do not want to grow up, will always be a child of thought; the use of large areas of color contrast, the combination of retro mood, so that women's beauty perfect show, but not a lack of emotional and lively girls [5]. By constantly upgrading colors and patterns, so that the impression more visible and effective deep-rooted interest in the clothing show.

Modern design clothing styles, through the integration of image and color, as well as Italian and environmental situation with the King, causing the pattern more lively and has a distinct image, so strong infection effect is formed. By means of artistic generalization, and continuous process improvement patterns, combined with a certain regularity between the organization and the use of a variety of technology tools, such as embroidery and screen printing, etc., based on clothing graphics, clothing prompted the appearance of the United States is effectively enriched and strengthened. Pop Art style of a variety of patterns, resulting in the modern fashion design a very big impact, a long time in the clothing market occupies absolute advantage and its style can appreciate the expression of interest. The use of cartoon images of children's clothing, clothing reflects the very good fun, this pattern occurs almost become the main style of modern children's clothing.

\section{Conclusion}

In short, with the continuous improvement of the current economy, more and more people began to pursue personalized. Clothing as a necessity of daily life, only a combination of people's needs to design, innovation from the clothing colors, fabrics, shapes and patterns and other clothing elements, so fun to get the show, so in order to allow more consumers to give meet, promote the development of China's garment industry.

\section{REFERENCE:}

[1] Chen Yao. fairy tale continues - on "childish" language in adult clothing design expression [J]. Arts Education, 2014,05: 222-223.

[2] Mo Qihua, Yao Guizhen, Wang Yao, Ma Jian。 based on emotional expression fun children clothing design principles [J]. Zhejiang Textile \& Fashion College, 2015,02: 27-31.

[3] Luo Fang. Clothing brand showcase interesting design based on the Experience Economy [J]. scientific and technological progress in the textile, 2011,04: 79-83.

[4] Dong Shuting, Analysis on interesting design apparel products under the Influence of Modernism [J]. Popular Literature, 2012,14: 101-102.

[5] Gu Wenjuan. factor in consumer demand for early childhood costume fun design [J]. Modern Silk Science and Technology, 2013,05: 184-186. 